searching for such an incentive ever since the pressure from unemployment has been relaxed.

1 Florence, P. Sargant, "Economics of Fatigue and Unrest" (London : Allen and Unwin, 1924).

${ }^{2}$ Long, J. R., "Labour Turnover under Full Employment", Monograph A2, University of Birmingham, Studies in Economics and Society, 1951.

s James, R., Econ. J., 59, No. 233 (1949).

- Cook, P. H., J. Inst. Personnel Management, 33, 2 (1951).

${ }^{\circ}$ Greystoke, J. R., Thomason, C. F., and Murphy, T. J., J. Inst. Personnel Management, 34, 158 (1952).

- Rice, A. K., Hill, J. M. M., and Trist, E. L., Human Relations, 3, No. 4 (1950).

7 Behrend, H., J. Indust. Econ., 2, No. 1 (1953).

"Woytinsky, W. S., "Three Aspects of Labour Dynamics" (Washington: Social Science Research Council, 1942).

* Behrend, H., Occupational Psychol., 27, No. 2 (1953).

10 Baldamus, W., Brit. J. Sociol., 2, No. 1 (1951).

\section{TOTAL SOLAR ECLIPSE OF JUNE 30,1954}

A TOTAL eclipse of the sun will occur on June 30,1954 , the belt of totality stretching from near Minneapolis, where eclipse comes at sunrise, through north-eastern Canada and Greenland, across the Faroes, Norway, Sweden, the Baltic and south Russia, finally ending at sunset not far from Pesha. war. Many European astronomers are proposing to go to southern Sweden to make observations, since this is an easily accessible portion of the eclipse track and the chances of a clear sky are reasonably good (about 50 per cent). Mid-eclipse comes near noon in the Faroes and in the early afternoon in Scandinavia. The belt of totality is about ninety miles wide, and near the centre line the duration of totality is $2 \frac{1}{2}$ minutes. The corona may be expected to be of the type associated with minimum sunspot activity. Preparations are known to be under way for parties of observers from Great Britain, Eire, France, Switzerland, Holland, West and East Germany, Italy and Canada. Swedish astronomers, who are naturally taking a very active interest, are organizing groups of observers to work at three or more separate places.

The Royal Greenwich Observatory is to send a small group to measure the gravitational deflexion of light by the sun. This is a fairly favourable eclipse for this purpose, as the star field is a good one, although the duration of totality is not specially long. Another group from Greenwich will be engaged in measuring accurate positions of the cusps for geodetic purposes. The Cambridge Observatories are planning several types of observation: (1) measurement of chromospheric line profiles with a large spectrograph giving a dispersion of about 1 A./mm. ; (2) measurement of the electron temperature of the chromosphere by Zanstra's method; (3) observation of the corona in the light of the green line 5303 A., using an interference filter and a FabryPerot interferometer of low resolving power, to examine the distribution of line width, and of line of sight motion. This last experiment is being carried out in co-operation with the St. Andrews Observatory. St. Andrews is also sharing a project with the Potsdam Observatory, to measure the deflexion of light by the sun with an elaborate apparatus developed from that used by Potsdam observers some twenty-five years ago in Sumatra. The University of London Observatory is to carry out photographic photometry of the corona, with a new arrangement which should reduce trouble from scattered light and also should extend the range of surface brightness measurable.
The Dunsink Observatory is to measure line-widths in the spectrum of the low chromosphere, using a Fabry-Perot interferometer.

All the foregoing parties will observe in various places in south Sweden. In addition, the Cambridge Observatories, with the help of the R.A.F., are photographing the outer corona in polarized light from an aircraft at about $30,000 \mathrm{ft}$. altitude, using a multi-lens camera designed for freedom from scattered light. Observers from the University of Edinburgh are also utilizing aircraft, in an attempt to detect a daylight aurora during totality. Both these flights will probably take place north of the Shetlands.

The plans of astronomers from other countries are not yet generally known; but a few details can be given here. French observers (MM. Dollfus and Michard) will use a spectrograph devised by the late Dr. B. Lyot, permitting photography of the coronal spectrum simultaneously around almost the whole sun. Dutch astronomers (Prof. M. G. J. Minnaert and Dr. J. Houtgast) will examine the Fraunhofer spectrum of the corona, and the distribution with respect to height of material in the chromosphere. Two Canadian parties intend to observe the chromospheric spectrum, one from the Dominion Astrophysical Observatory, Victoria, B.C., with a slitless instrument, the other from the Dominion Observatory, Ottawa, with a high-dispersion slit spectrograph.

\section{OBITUARY}

\section{Dr. Karl B. McEachron}

Dr. KarL B. McEAcHroN, consultant to the General Electric Company at Pittsfield, New York, died in hospital on January 24, aged sixty-four years.

Dr. McEachron's name will always be associated with high-voltage research work and with the study of lightning. He was an instructor for some years in the Ohio Northern University and at Purdue, and in 1922 took charge of the research and development section of the Lightning Arrester Engineering Department of the Pittsfield factory of the General Electric Company. Here he developed techniques for producing and recording electrical transients of very short duration, and was one of the first engineers to apply surges from an impulse generator directly to overhead transmission lines in order to study the attenuation of high travelling-wave voltages and their effect on terminal apparatus. $\mathrm{He}$ was largely responsible for the successful production of the 'Thyrite' lightning arrester, embodying material composed of carborundum and graphite having a fourth-power voltage/current characteristic. His published work on this development is to be found in the Transactions of the American Institute of Electrical Engineers in the years 1928-33, and for this he received the Charles A. Coffin Award of the Edison Electric Institute in 1931 and the Longstreth Medal of the Franklin Institute in 1936.

In 1933 Dr. McEachron was appointed engineerin-charge of the High Voltage Engineering Laboratory at Pittsfield and there began the study of lightning flashes striking transmission lines and-laterstriking to the top of the Empire State Building, New York. $\mathrm{He}$ installed oscillographs on the top floor connected to the radio antennæ system of the National Broadcasting Company twelve hundred and fifty feet above street-level and placed a variety of types of Boys's cameras on the fifty-sixth floor of 